Article

\title{
Neuroanatomical Changes in Leber's Hereditary Optic Neuropathy: Clinical Application of 7T MRI Submillimeter Morphometry
}

\author{
Kamil Jonak $^{1,2, * \mathbb{C}}$, Paweł Krukow ${ }^{3} \mathbb{D}$, Mark Symms ${ }^{4}$, Ryszard Maciejewski ${ }^{5}$ \\ and Cezary Grochowski ${ }^{6, *(D)}$ \\ 1 Department of Biomedical Engineering, Lublin University of Technology, 20-618 Lublin, Poland \\ 2 Department of Psychiatry, Psychotherapy and Early Intervention, Medical University of Lublin, \\ 20-439 Lublin, Poland \\ 3 Department of Clinical Neuropsychiatry, Medical University of Lublin, 20-439 Lublin, Poland; \\ pawelkrukow@umlub.pl \\ 4 GE Healthcare, Amersham Place, Amersham HP7 9NA, UK; MarkRoger.Symms@ge.com \\ 5 Department of Anatomy, Medical University of Lublin, 20-400 Lublin, Poland; maciejewski.r@gmail.com \\ 6 Laboratory of Virtual Man, Medical University of Lublin, 20-400 Lublin, Poland \\ * Correspondence: jonak.kamil@gmail.com (K.J.); cezary.grochowski@o2.pl (C.G.)
}

Received: 14 May 2020; Accepted: 5 June 2020; Published: 9 June 2020

\begin{abstract}
Leber's hereditary optic neuropathy (LHON) is one of the mitochondrial diseases that causes loss of central vision, progressive impairment and subsequent degeneration of retinal ganglion cells (RGCs). In recent years, diffusion tensor imaging (DTI) studies have revealed structural abnormalities in visual white matter tracts, such as the optic tract, and optic radiation. However, it is still unclear if the disease alters only some parts of the white matter architecture or whether the changes also affect other subcortical areas of the brain. This study aimed to improve our understanding of morphometric changes in subcortical brain areas and their associations with the clinical picture in LHON by the application of a submillimeter surface-based analysis approach to the ultra-high-field 7T magnetic resonance imaging data. To meet these goals, fifteen LHON patients and fifteen age-matched healthy subjects were examined. For all individuals, quantitative analysis of the morphometric results was performed. Furthermore, morphometric characteristics which differentiated the groups were correlated with variables covering selected aspects of the LHON clinical picture. Compared to healthy controls (HC), LHON carriers showed significantly lower volume of both palladiums (left $p=0.023$; right $p=0.018)$, the right accumbens area $(p=0.007)$ and the optic chiasm $(p=0.014)$. Additionally, LHON patients have significantly higher volume of both lateral ventricles (left $p=0.034$; right $p=0.02$ ), both temporal horns of the lateral ventricles (left $p=0.016$; right $p=0.034)$, 3rd ventricle $(p=0.012)$ and 4 th ventricle $(p=0.002)$. Correlation between volumetric results and clinical data showed that volume of both right and left lateral ventricles significantly and positively correlated with the duration of the illness (left $R=0.841, p=0.002$; right $R=0.755, p=0.001$ ) and the age of the LHON participants (left $R=0.656, p=0.007$; right $R=0.691, p=0.004$ ). The abnormalities in volume of the LHON patients' subcortical structures indicate that the disease can cause changes not only in the white matter areas constituting visual tracts, but also in the other subcortical brain structures. Furthermore, the correlation between those results and the illness duration suggests that the disease might have a neurodegenerative nature; however, to fully confirm this observation, longitudinal studies should be conducted.
\end{abstract}

Keywords: LHON; 7T MRI; morphometry; illness duration; mitochondrial 


\section{Introduction}

Leber's hereditary optic neuropathy $(\mathrm{LHON})$ is one of the most frequent mitochondrial diseases of the optic nerve [1], characterized by maternally inherited genetic disorder, with young male predilection and loss of central vision, which is almost always bilateral and severe [2,3]. Although the disease was described for the first time in 1871 by the ophthalmologist Theodor Leber [4], it took researchers more than 100 years to identify several mutations in the mitochondrial DNA (mtDNA) that would affect mitochondrial oxidative phosphorylation [5,6]. Pathologically, changes in LHON show retinal ganglion cell degeneration with the axonal loss of the optic nerve and the thickening of the retinal nerve fiber layer (RNFL) [7]. These changes result in a decline in visual acuity (VA), permanent central scotoma and optic nerve atrophy.

Accelerated development of magnetic resonance imaging (MRI) methods allow researchers and clinicians to assess the neurodegenerative processes in many types of diseases associated with progressive blinding [8-12]. Anatomical changes observed in the LHON patients were consistent with the clinical picture of the disease. Studies have reported atrophy and increased T2-weighted signal intensity in the optic nerves [13,14], structural damage of the visual cortex and retinofugal pathway, which could be related to axonal degeneration secondary to the loss of retinal ganglion cells [15,16]. Recent studies with the application of diffusion transfer imagining (DTI) showed a significant decrease in fractional anisotropy (FA) in LHON patients [17] and revealed a microstructural alteration of the white matter (WM) [18].

Applications of the MRI method to measure neuronal atrophy are regarded as valid markers of disease state and progression [19]. However, variability in the shape and neuroanatomical configuration of individual brains may cause overlooking of structural differences by visual inspection or volume of interest (VOI) techniques. For more precise assessment of brain structure changes, voxel-based morphometry (VBM) and the surface-based (SB) approach have been applied to MRI analysis [20,21]. The VBM and SB methods are automated techniques that enable an assessment of the structure of the brain at the level of the voxel and appear to be well-established techniques for assessment of brain tissue loss in a wide spectrum of patients [22-26]. Morphometric studies with the application of VBM into Leber's hereditary optic neuropathy showed reduction of the volume in the optic chiasm, optic tract, optic radiations and primary visual cortex [15]. Additionally, visual cortex changes were significantly correlated with global and temporal peripapillary retinal nerve fiber layer thickness [15]. Studies based on SB analysis in LHON revealed that the optic tract and the optic radiation differ from controls in radial and axial diffusivity [17].

Despite the mentioned MRI-based studies investigating LHON, it is still unclear how the disease, and its functional consequences associated with blindness, might influence individual subcortical structures, for example its volume. Previous researchers, who have confirmed the occurrence of gradual degeneration associated with prolonged duration of the disease, observed a unique process in which the RNFL changed from thickening in the acute stage to thinning in the subacute or chronic phase in LHON patients [27], as well as finding a significant correlation with the abnormalities within resting state brain networks [28]. Additionally, there is also a lack of publications describing detailed morphometric results from main subcortical brain structures such as basal ganglia or ventricles in the LHON patients. One of the reasons for this might be the fact that previous inquiries were based on 1.5 and 3T scanners giving less precise parcellation and segmentation results compared with 7T scanners [29,30]. Usage of 7T MRI machines enriches the images with spatial details not visible at lower field strengths due to the possibility of acquiring data with a higher resolution and Contrast to Noise Ratio (CNR), but without increasing the scan time [31]. High-field MRIs can also generate images with significantly improved contrast between deep brain grey matter tissue and WM [32]. Application of submillimeter voxel analysis to MRI volumetric study could substantially master the brain parcellation and segmentation effect and give more robust volumetric results [33]. Some studies have already provided evidence of improved identification of disease-specific morphological changes in the brains of patients with multiple sclerosis and Alzheimer's disease using 7 T versus 3 T MRIs [34,35]. Ultra-high-field imaging 
also has enhanced sensitivity to detect fine-scale structural [36,37] and functional properties and changes in the brain [38]. Nevertheless, in accordance with our knowledge, there are no studies focused on morphological changes in the brains of LHON patients estimated with the application of ultra-high-field 7T MRI.

This study had two specific goals. First, we examined if there were any changes in subcortical structures associated with LHON disease. Previous studies clearly showed decreased volume of optic radiation and chiasm, changes in oxygen consumption [39], antioxidants [40], phosphorylation and mitochondrial ATP production [41] in LHON patients. Although, it is still unknown whether LHON mutations have a direct effect on subcortical brain structural properties. Second, our study is the first application of submillimeter high-field MRI for the evaluation of morphometric changes in LHON patients. The high precision of 7T MRI could reveal some significant associations between brain abnormalities and selected features of this disease's clinical picture. Establishing such significant relationships might deepen the current knowledge regarding disease progression and its neuroanatomical basis. This applies first of all to the question regarding stability or progression of neuroanatomical changes accumulating with patients' age and duration of illness.

\section{Methods}

\subsection{Subjects}

Initially, twenty-five patients with LHON were selected from a national health database. However, only 15 of them met the final inclusion criteria, which were the following: 11778G > A mitochondrial DNA mutation confirmed by genetic tests, participants couldn't have known pathologies within the cerebrovascular system, were capable of signing informed consent, were over 18 years old, had at least 10 years of regular education and no familial history of severe neuropsychiatric disorders which would additionally affect the state of the nervous system. The patients did not suffer from hypertension, diabetes and any neurodegenerative or neurological diseases. Additionally, patients with any metallic implant, who were pregnant or breastfeeding, as well as those suffering from claustrophobia, were excluded from the study. Radiological assessment was carried out by an experienced neuroradiologist (25 years of experience) and a neuroanatomy specialist (40 years of experience). The healthy controls (HC) group was recruited from the local community after the clinical group was completed to guarantee the demographic matching of individuals from both samples. All of the participants were right-handed non-smokers with no history of chronic alcohol consumption. Blood pressure was measured in all participants and no abnormalities were found. All participants signed informed consent. This research was approved by the local medical ethics committee of the Medical University of Lublin (KE-0254/23/2017) and was carried out in compliance with national legislation and the Declaration of Helsinki. The scans were obtained at the Ecotech Complex, Lublin, Poland.

\subsection{MRI Acquisition}

Three-dimensional inversion recovery-prepared spoiled gradient echo (3D-SPGR "BRAVO") was acquired from the 7T MRI with 32-channel coil at the Ecotech Complex, Lublin. Field of view was $220 \times 220 \times 180 \mathrm{~mm}$ and the acquisition matrix was $256 \times 256 \times 180$. The images were reconstructed to a $512 \times 512$ matrix, giving a final voxel size of $0.43 \times 0.43 \times 1 \mathrm{~mm}$. TE $2.6 \mathrm{~ms}$, TR $6.6 \mathrm{~ms}$, TI $450 \mathrm{~ms}$, Flip angle 12 degrees, bandwidth $+/-31.25 \mathrm{kHz}$. Parallel imaging (ARC) factor 2 was used.

\subsection{Image Analysis}

The first step of analysis was the application of bias correction algorithms in SPM12 (http://www.fil.ion.ucl.ac.uk/spm; MATLAB R2018A version, Mathworks, Inc, Natick, MA, USA). Due to high field inhomogeneity in 7T MRI each structural volume was intensity bias corrected using the unified segmentation process [20]. Brain segmentation and volume calculations were performed using FreeSurfer (version 7.0) (https://surfer.nmr.mgh.harvard.edu). In this study we have 
not used the normal recon-all procedure but the submillimeter version of the recon-all procedure [33]. Nevertheless, the submillimeter recon-all procedure normal steps of data reconstructions, such as skull stripping, volumetric registration, normalization, volumetric labelling, segmentation, smoothing and cortical parcellation are also included (https://surfer.nmr.mgh.harvard.edu/fswiki/recon-all). As the submillimeter reconstruction was unstable with our native voxel size, we thus down-sampled voxel size into $0.5 \mathrm{~mm}^{3}$. During the pipeline procedure every participant's brainmask was manually fixed by the radiologist and the surface inflation number was 100. After the initial preprocessing, quality assessment was conducted by the radiologist as well. Each slice was visually inspected for skull stripping errors, segmentation errors, normalization errors pial surface errors, and topological defects, following the FreeSurfer guidelines. The appropriate preprocessing steps were then repeated for the participants whose images required editing. After that, tabulated data of the segmented results were collected using two FreeSurfer summarizing scripts (i.e., aparcstats2table and asegstats2table).

\subsection{Statistical Analysis}

Due to the relatively small number of participants in each of the research groups, and the results of Shapiro-Wilk test showing non-compliance of our volumetric data with the normal distribution, groups were compared using the two-sided, non-parametric Mann-Whitney U-test for independent samples $(z)$, with the statistical significance threshold set at $p<0.05$. Each volumetric variable was individually compared between groups. The $\chi^{2}$ test was applied to compare groups for qualitative variables, such as sex. After determining between-group differences regarding volumetric variables, these metrics, which significantly differentiated the groups, were included in the further step of the analysis. This consisted of establishing potential correlations between volumetrically altered structures and selected demographic and clinical variables in the LHON group, such as age and duration of illness. Correlation analysis regarding mentioned individual variables was carried out using the non-parametric Spearman R test. The level of statistical significance (ultimately $p<0.05$ ) was corrected for the number of performed tests according to the false discovery rate (FDR) method.

\section{Results}

\subsection{Participants}

Table 1 presents demographic and clinical data on the studied groups. Samples did not differ significantly in terms of age ( $\mathrm{LHON}=36.21 ; \mathrm{HC}=32.53)$, sex (LHON $=86 \%$ male; $\mathrm{HC}=66 \%$ male) or years of education $(\mathrm{LHON}=15.33 ; \mathrm{HC}=16)$. In the LHON group, the duration of the illness lasted for about 10 years.

Table 1. Demographic and clinical data of research groups.

\begin{tabular}{ccccc}
\hline & $\begin{array}{c}\text { LHON } \\
(\boldsymbol{n}=\mathbf{1 5}) \\
\mathbf{M}(\mathrm{SD})\end{array}$ & $\begin{array}{c}\text { HC } \\
(\boldsymbol{n}=\mathbf{1 5}) \\
\mathbf{M} \text { (SD) }\end{array}$ & $\boldsymbol{z}$ Value or $\chi^{2}$ & $p$ \\
\hline Age (years) & $36.21(14.41)$ & $32.53(7.42)$ & 0.024 & 0.981 \\
Education (years) & $15.33(1.98)$ & $16(1.55)$ & -1.823 & 0.674 \\
Sex (\% male) & 86 & 66 & 1.671 & 0.192 \\
Duration of illness (months) & $132(144.32)$ & & -1.823 & 0.674 \\
Education (years) & $15.33(1.98)$ & $16(1.55)$ & 1.671 & 0.192 \\
Sex (\% male) & 86 & 66 & & \\
Duration of illness (months) & $132(144.32)$ & & &
\end{tabular}

\subsection{Volumetric Differences between Groups}

Table 2 presents results of volumetric analysis regarding HC and LHON groups. Statistical analysis revealed that compared to $\mathrm{HC}$, LHON patients had significantly lower volume of both palladiums 
(left $p=0.023$; right $p=0.018)$, right accumbens area $(p=0.007)$ and the optic chiasm $(p=0.014)$ (Figure 1). Additionally, LHON patients had significantly higher volume of both lateral ventricles (left $p=0.034$; right $p=0.02$ ), both temporal horns of lateral ventricles (left $p=0.016$; right $p=0.034$ ), 3rd ventricle $(p=0.012)$ and 4 th ventricle $(p=0.002)$ (Figure 1$)$.

Table 2. Results of volumetric analysis (mm3).

\begin{tabular}{|c|c|c|c|c|}
\hline & LHON ( $N=15)$ & $\mathrm{HC}(N=15)$ & & \\
\hline & $\mathbf{M}$ & $\mathbf{M}$ & $Z$ & $p$ \\
\hline Left lateral ventricle & 10,246 & 6646 & 2.115 & 0.035 * \\
\hline Temporal horn of left lat-vent & 567 & 289 & 2.406 & $0.016^{*}$ \\
\hline Left Cerebellum WM & 20,581 & 19,375 & 0.249 & 0.804 \\
\hline Left Cerebellum Cortex & 52,479 & 53,110 & 0.415 & 0.678 \\
\hline Left Thalamus & 7507 & 7205 & -0.249 & 0.804 \\
\hline Left Caudate & 3786 & 3942 & -0.124 & 0.901 \\
\hline Left Putamen & 5616 & 5262 & 0.539 & 0.590 \\
\hline Left Pallidum & 1509 & 1727 & -2.281 & 0.023 * \\
\hline 3rd Ventricle & 1628 & 1314 & 2.489 & 0.013 * \\
\hline 4th Ventricle & 2931 & 1996 & 3.069 & $0.002 *$ \\
\hline Left Hippocampus & 3944 & 3989 & 0.249 & 0.804 \\
\hline Left Amygdala & 1364 & 1412 & -0.332 & 0.740 \\
\hline Cerebrospinal fluid & 1789 & 1488 & 0.747 & 0.455 \\
\hline Left Accumbens area & 553 & 499 & 0.664 & 0.507 \\
\hline Left Choroid plexus & 384 & 335 & 0.830 & 0.407 \\
\hline Right lateral ventricle & 8276 & 6179 & 2.323 & 0.020 * \\
\hline Temporal horn of right lat-vent & 414 & 305 & 2.115 & 0.034 * \\
\hline Right Cerebellum WM & 1,9727 & 1,7227 & 1.078 & 0.281 \\
\hline Right Cerebellum Cortex & 5,2944 & 5,1682 & 0.249 & 0.804 \\
\hline Right Thalamus & 7119 & 7378 & -0.041 & 0.967 \\
\hline Right Caudate & 4064 & 3864 & 0.995 & 0.320 \\
\hline Right Putamen & 5875 & 5542 & 0.788 & 0.431 \\
\hline Right Pallidum & 1236 & 1531 & -2.364 & 0.018 * \\
\hline Right Hippocampus & 3992 & 3761 & 1.908 & 0.056 \\
\hline Right Amygdala & 1666 & 1666 & 0.041 & 0.967 \\
\hline Right Accumbens area & 555 & 711 & -2.696 & $0.007^{*}$ \\
\hline Right Choroid plexus & 414 & 381 & 0.664 & 0.508 \\
\hline Optic Chiasm & 96 & 158 & -2.530 & 0.011 * \\
\hline CC Posterior & 573 & 671 & -0.456 & 0.648 \\
\hline CC Mid Posterior & 548 & 477 & -0.166 & 0.868 \\
\hline CC Central & 506 & 476 & -0.166 & 0.868 \\
\hline CC Mid Anterior & 524 & 520 & -0.083 & 0.934 \\
\hline CC Anterior & 921 & 823 & 0.290 & 0.772 \\
\hline Left Cortex & 251,888 & 248,114 & 0.456 & 0.648 \\
\hline Right Cortex & 255,895 & 244,263 & 0.539 & 0.590 \\
\hline Cortex & 506,176 & 496,939 & 0.581 & 0.561 \\
\hline Left Cerebral WM & 228,307 & 239,037 & -0.373 & 0.709 \\
\hline Right Cerebral WM & 238,648 & 248,453 & -0.083 & 0.934 \\
\hline WM & 459,714 & 487,491 & -0.332 & 0.740 \\
\hline Sub-cortical GM & 57,462 & 57,970 & -0.166 & 0.868 \\
\hline Total GM & 670,972 & 664,681 & 0.456 & 0.648 \\
\hline
\end{tabular}

Note. CC-Corpus callosum, WM-White matter, GM-Gray matter, lat-vent-Lateral ventricle, M-Median, SD-Standard derivation, Z-Mann-Whitney test, ${ }^{*}$ - significant difference between groups. 


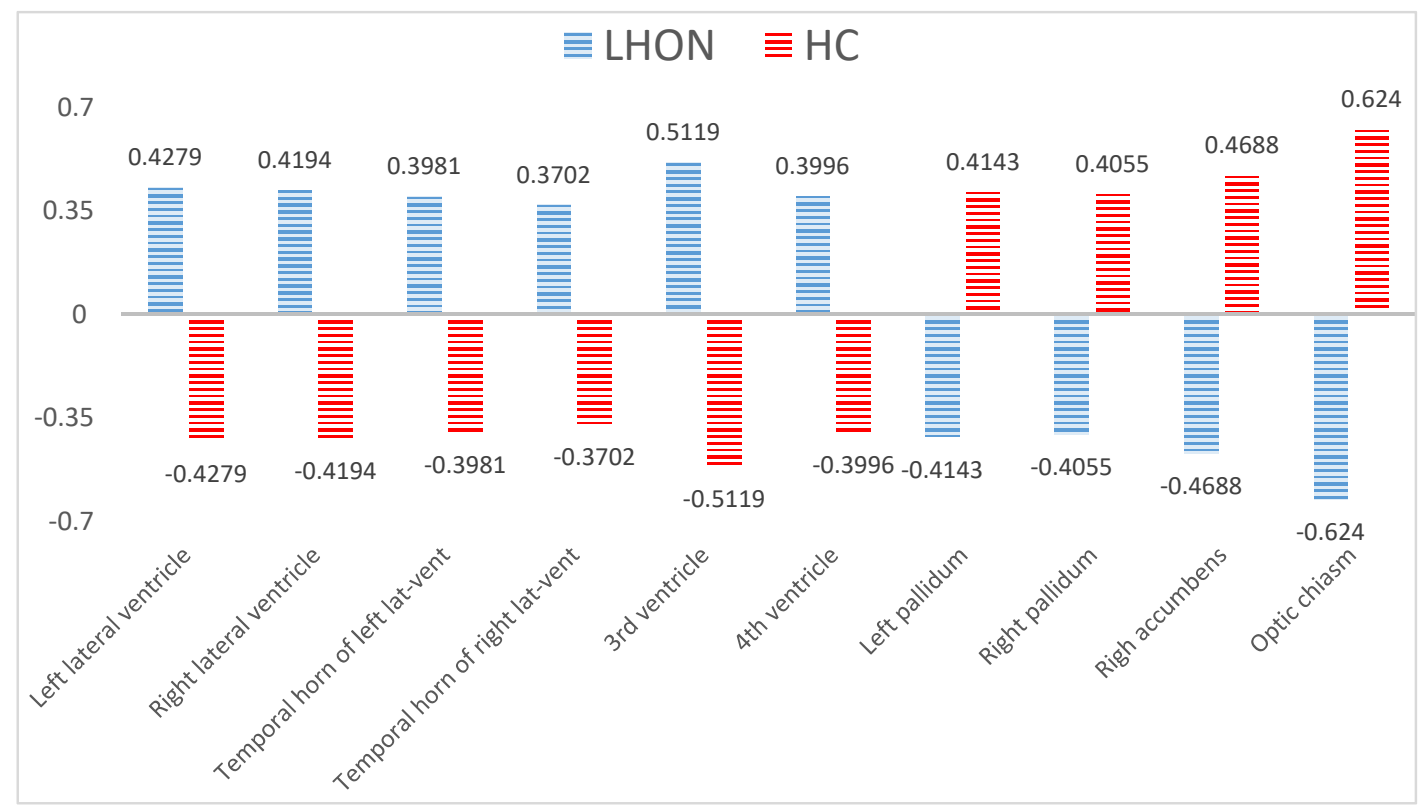

Figure 1. The figure displays a standardized volumetric data (z-scores) of ten neural structures significantly differing the groups according to non-parametric Mann-Whitney U-test. The raw volumetric indicators were standardized to cover results ranging from 96 to $10,246 \mathrm{~mm} 3$ and jointly show them in one line. The mean for both groups taken together was 0 . Volumes of the 3rd ventricle and optic chiasm differentiated the groups for the most extent. The z-standardization of these result was made only for presentational purposes.

\subsection{Associations between Volumetric Results and Clinical Data of LHON Participants}

Analyses of relationships between volumetric data and clinical characteristics showed that volumes of both right and left lateral ventricles significantly and strongly correlated with the duration of the illness (left $R=0.841, p=0.002$; right $R=0.755, p=0.001$ ) (Figure 2) and age of participants from the LHON group (left $R=0.656, p=0.007$; right $R=0.691, p=0.004$ ). Figure 3 shows cross-sectional 7T MRI/T1 images of several LHON patients at four stages of disease duration $(0-5,5-15,15-25,25+$; years) and age and sex-matched healthy controls. The qualitative comparison of these images suggests accelerated neural atrophy and enlargement of lateral ventricles in LHON patients compared with controls, which is in line with strong correlations between volume of ventricles and duration of illness in the LHON sample.
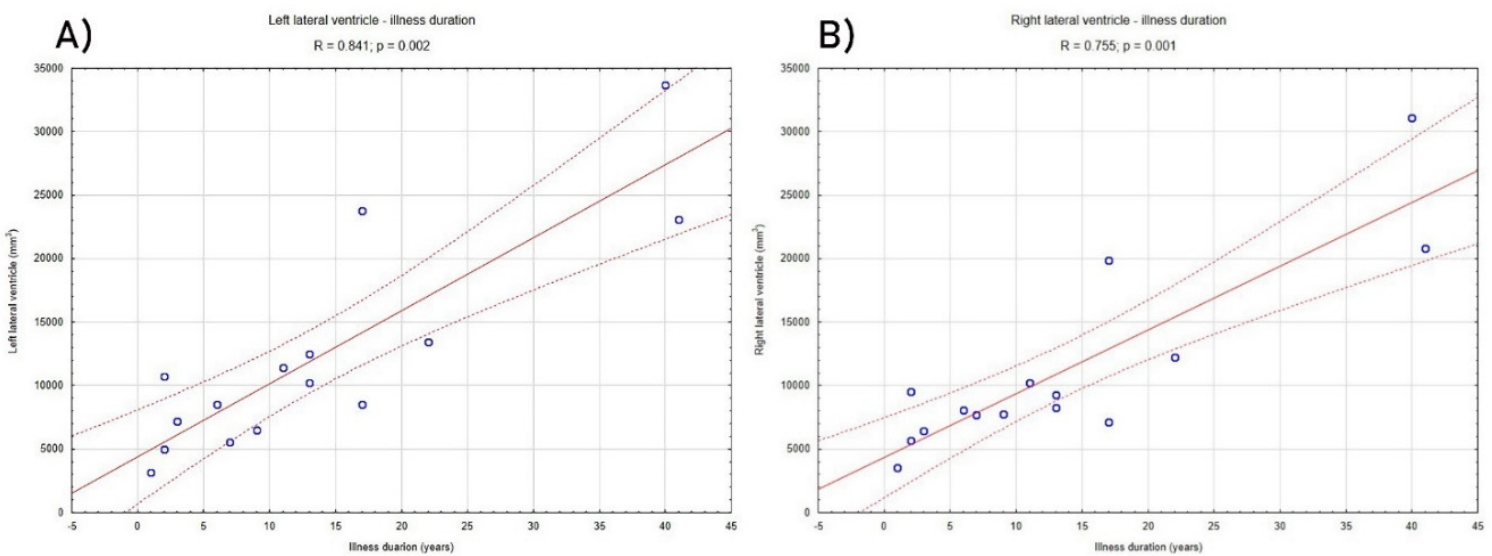

Figure 2. The figure shows correlation between duration of illness and the volume of left (A) and right (B) lateral ventricle in the LHON patients. $p$-value and $R$ values were calculated using the non-parametric Spearman $R$ test. 


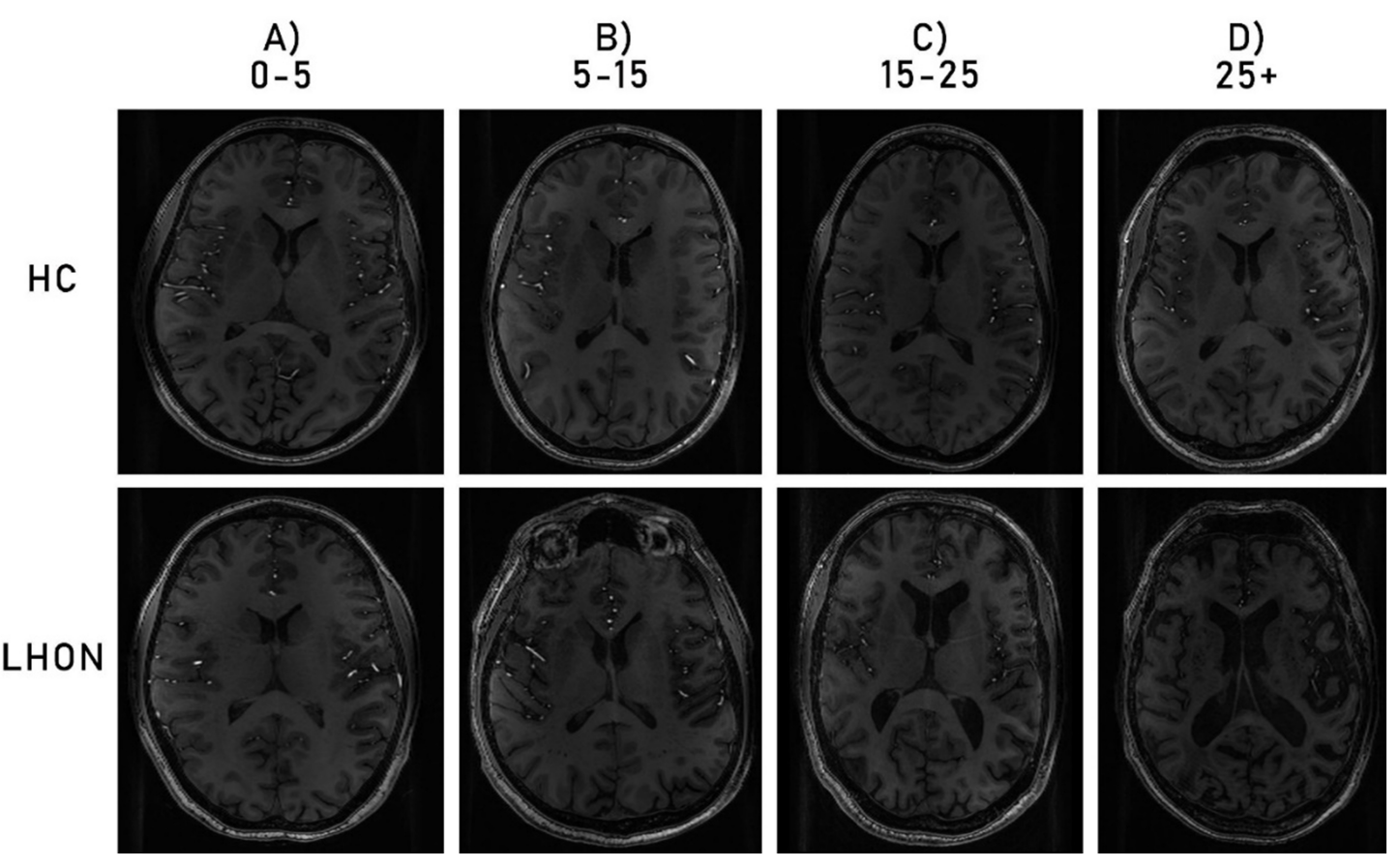

Figure 3. Comparison of $\mathrm{T} 1$ images from four LHON participants with different duration illness (A) 0-5 years; (B) 5-15 years; (C) 15-25 years; (D) 25+ years; with four HC participants of similar age and gender.

\section{Discussion}

In this study we showed the first application of submillimeter surface-based morphometry of ultra-high-field MRI data to investigate possible volumetric abnormalities of brain structures in LHON patients. Moreover, we have demonstrated that those neuronal changes were associated with selected features of the disease's clinical picture. The most important findings were that compared to controls, LHON patients showed significantly decreased volume in a set of subcortical grey matter nuclei, including both palladiums, the right accumbens area and the optic chiasm. Additionally, LHON subjects have significantly higher volume of both lateral ventricles, both temporal horns of lateral ventricles, 3 rd ventricle and 4 th ventricle. All of these findings have met our major goal, which was to verify whether the brain abnormalities in LHON patients are limited only to brain areas constituting the visual system. Our main outcomes suggest that volumetric characteristics of selected subcortical structures not belonging to the visual system in LHON patients are also significantly altered. We have additionally documented significant correlations between some of the mentioned altered volume variables and clinical data in the LHON group. Correlations between volumetric results and clinical characteristics showed that the volume of both right and left lateral ventricles was significantly associated with the duration of the illness and the age of LHON participants. Observed results indicate that brain abnormalities in mitochondrial disease like LHON can progress with patients' age and duration of illness.

\subsection{Brain Morphological Abnormalities of the LHON Participants}

Implementation of submillimeter surface-based morphometry into ultra-high-field MRI turned out to be robust tool for brain morphometric analysis in the LHON group. In the previous study, LHON patients had significant reduced volume of the bilateral primary visual cortex GM and reduced WM volume in the optic chiasm, optic tract-areas located in the optic radiations [15]. Reduction of optic chiasm volume, established also in our results, once again confirms how sensitive areas of the visual pathway are to the LHON disease. Compared with previous studies using 3T [42] and 1.5T MRIs [43], ultra-high-field 7T MRI also showed decreased volume of both pallidums and the 
right accumbens, which has not been reported earlier in LHON patients. Nevertheless, recent studies that also include Leber plus patients (LHON patients with dystonia) reported increased T2 signal intensity in the basal ganglia area; however, those cases are connected with a different mtDNA mutation: 10197G > A [44]. Furthermore, except for reduced volumetric parameters in LHON patients, we have also observed enlarged ventricular brain systems in this sample. Earlier investigations were focused on optic neuropathies and reported many WM abnormalities, specifically within the optic tract fibers [18]. Recent studies that combined DTI and quantitative T1 (qT1) measurements revealed volume loss along the optic radiation and suggested that the microstructural origins of the diffusivity changes can be different between the tracts, but the mechanisms of the myelin loss and abnormalities in diffusion parameters remain unclear [17]. In the current study we have not analyzed specific WM tracts, although several volumetric abnormalities in the brain ventricular systems of LHON patients were noticed. These findings could be a consequence of changes in several WM areas of the brain in LHON patients; hence, ventricular enlargement may be associated with progressive atrophy of different WM fibers in the brain.

\subsection{Associations with Clinical Characteristics}

Besides the mentioned morphometric anomalies, we have also revealed significant positive and strong correlations between the volume of ventricles and the LHON duration of the illness. Although there were also correlations between the same structures and the age of LHON participants, we have not found any significant correlations between age and ventricle volume in the controls group; therefore, it seems likely that progressive enlargement of ventricles was associated only with the age of LHON participants. Some previous studies confirmed that the duration of illness in the LHON group was correlated with the macular choroidal thickness [45]. Nevertheless, DTI studies focused on optic nerve quantitative assessment between chronic LHON patients and normal control subjects showed no correlation between illness duration and DTI parameters and suggest that damage along the visual pathways may occur relatively early from the disease's clinical onset, or could be already present when the first symptoms are reported by the patient [46]. Ophthalmologic studies focused on the progressive changes in LHON patients showed structural changes in the ganglion cell layer and inner plexiform layer [47], as well as RNFL thickening [27]. Ventricle enlargement and increased CSF volume are reliable morphometric features of neural atrophy. These phenomena were observed in such typical neurodegenerative diseases as mild cognitive impairment, Alzheimer's disease [48], Parkinson's disease [49], Huntington's disease [50] and in patients after traumatic brain injury (TBI) [51]. Considering the discussed findings, our study suggests, probably for the first time, that in LHON patients neurodegenerative changes might occur, and do not involve only those neural areas which are the major parts of the brain's visual system.

\subsection{Limitations}

Some limitations must be considered when interpreting our results. Firstly, we have not used T2 data to improve pial surfaces during the segmentation protocol in Freesurfer software; however, pial surface errors were manually examined and corrected by a neurologist during the analysis. Second, our final sample size was limited to only fifteen patients, which might at least partially reduce the statistical power of the main findings. There is no doubt that future studies need to include a larger sample in order to confirm our findings. Third, it would be beneficial to directly compare LHON-related morphometric results taken from 1.5T, 3T and 7T MRI scanners to precisely verify the assumption that ultra-high-field morphometry originating from the 7T scanner brings substantially improved data compared with those obtained from 1.5T or 3T scanners. Furthermore, to analyze the relationship between the volume loss of subcortical structures and the atrophy of the white matter fibers that form the visual pathway, a hybrid study that combines submillimeter morphometry and diffusion imaging should be done in an LHON cohort. Additionally, we did not conduct an additional examination of ophthalmic parameters of our patients, due to the fact that according to information taken from 
them in the initial interview, patients described themselves as functionally blind. The statistical analysis regarding group differences of the volumetric indicators was conducted with a relatively simple, non-parametric test, which did not control for potential confounds such as demographic characteristics. However, as stated earlier, participants included in the final research groups were very alike in this respect, which, in our opinion, justified application of a direct variable comparison with a non-parametric test.

\section{Conclusions}

In conclusion, this is the first study that utilized ultra-high field MRI data for quantification of volumetric, subcortical brain changes in a representative population of LHON patients. Comparative analysis between controls and LHON patients revealed decreased volume in subcortical brain structures: both pallidums and the right accumbens area. Additionally, increased volume of brain ventricular systems occurred. The observed enlargement of both right and left lateral ventricles significantly and strongly correlated with the duration of the illness, which is of special interest, considering that this is the first study with such an observation in this particular group of patients. Nevertheless, future longitudinal quantitative MRI and in vitro studies are necessary to track the progression of the detected morphological changes in Leber's disease.

Author Contributions: Conceptualization: K.J.; Investigation: K.J., C.G.; Funding acquisition: C.G., R.M.; data analysis and visualization, K.J.; data acquisition M.S.; writing original draft: K.J., C.G., P.K., M.S.; critical revised the clinical interpretation of our findings, C.G., R.M. All authors were critically involved in the theoretical discussion and composition of the manuscript. All authors have read and agreed to the published version of the manuscript.

Funding: This research received no external funding.

Acknowledgments: We would like to thank Robert Rejdak, Chief of the Department of General Ophthalmology for sharing the contact to LHON patients.

Conflicts of Interest: The authors declare no conflict of interest.

\section{References}

1. Wallace, D.C.; Singh, G.; Lott, M.T.; Hodge, J.A.; Schurr, T.G.; Lezza, A.M.S.; Elsas, L.J.; Nikoskelainen, E.K. Mitochondrial DNA mutation associated with Leber's hereditary optic neuropathy. Science 1988, 242, 1427-1430. [CrossRef] [PubMed]

2. Newman, N.J.; Lott, M.T.; Wallace, D.C. The clinical characteristics of pedigrees of Leber's hereditary optic neuropathy with the 11778 mutation. Am. J. Ophthalmol. 1991, 111, 750-762. [CrossRef]

3. McFarland, R.; Turnbull, D.M. Batteries not included: Diagnosis and management of mitochondrial disease. J. Intern. Med. 2009, 265, 210-228. [CrossRef]

4. Carelli, V.; Ross-Cisneros, F.N.; Sadun, A.A. Mitochondrial dysfunction as a cause of optic neuropathies. Prog. Retin. Eye Res. 2004, 23, 53-89. [CrossRef] [PubMed]

5. Tońska, K.; Kodroń, A.; Bartnik, E. Genotype-phenotype correlations in Leber hereditary optic neuropathy. Biochim. Biophys. Acta 2010, 1797, 1119-1123. [CrossRef]

6. Mackey, D.; Howell, N. A variant of Leber hereditary optic neuropathy characterized by recovery of vision and by an unusual mitochondrial genetic etiology. Am. J. Hum. Genet. 1992, 51, 1218-1228.

7. Yu-Wai-Man, P.; Griffiths, P.G.; Hudson, G.; Chinnery, P.F. Inherited mitochondrial optic neuropathies. J. Med. Genet. 2009, 46, 145-158. [CrossRef]

8. Chen, W.W.; Wang, N.; Cai, S.; Fang, Z.; Yu, M.; Wu, Q.; Tang, L.; Guo, B.; Feng, Y.; Jonas, J.B.; et al. Structural brain abnormalities in patients with primary open-angle glaucoma: A study with 3T MR imaging. Investig. Ophthalmol. Vis. Sci. 2013, 54, 545-554. [CrossRef]

9. Zikou, A.K.; Kitsos, G.; Tzarouchi, L.C.; Astrakas, L.; Alexiou, G.A.; Argyropoulou, M.I. Voxel-based morphometry and diffusion tensor imaging of the optic pathway in primary open-angle glaucoma: A preliminary study. Am. J. Neuroradiol. 2012, 33, 128-134. [CrossRef]

10. Li, C.; Cai, P.; Shi, L.; Lin, Y.; Zhang, J.; Liu, S.; Xie, B.; Shi, Y.; Yang, H.; Li, S.; et al. Voxel-based morphometry of the visual-related cortex in primary open angle glaucoma. Curr. Eye Res. 2012, 37, 794-802. [CrossRef] 
11. Plank, T.; Frolo, J.; Brandl-Rühle, S.; Renner, A.B.; Hufendiek, K.; Helbig, H.; Greenlee, M.W. Gray matter alterations in visual cortex of patients with loss of central vision due to hereditary retinal dystrophies. Neuroimage 2011, 56, 1556-1565. [CrossRef]

12. Boucard, C.C.; Hernowo, A.T.; Maguire, R.P.; Jansonius, N.M.; Roerdink, J.B.T.M.; Hooymans, J.M.M.; Cornelissen, F.W. Changes in cortical grey matter density associated with long-standing retinal visual field defects. Brain 2009, 132, 1898-1906. [CrossRef]

13. Morrissey, S.P.; Borruat, F.X.; Miller, D.H.; Moseley, I.F.; Sweeney, M.G.; Govan, G.G.; Kelly, M.A.; Francis, D.A.; Harding, A.E.; McDonald, W.I. Bilateral simultaneous optic neuropathy in adults: Clinical, imaging, serological, and genetic studies. J. Neurol. Neurosurg. Psychiatry 1995, 58, 70-74. [CrossRef]

14. Kermode, A.G.; Moseley, I.F.; Kendall, B.E.; Miller, D.H.; Macmanus, D.G.; McDonald, W.I. Magnetic resonance imaging in Leber's optic neuropathy. J. Neurol. Neurosurg. Psychiatry 1989, 52, 671-674. [CrossRef]

15. Barcella, V.; Rocca, M.A.; Bianchi-Marzoli, S.; Milesi, J.; Melzi, L.; Falini, A.; Pierro, L.; Filippi, M. Evidence for retrochiasmatic tissue loss in Leber's hereditary optic neuropathy. Hum. Brain Mapp. 2010, 31, 1900-1906. [CrossRef]

16. Milesi, J.; Rocca, M.A.; Bianchi-Marzoli, S.; Petrolini, M.; Pagani, E.; Falini, A.; Comi, G.; Filippi, M. Patterns of white matter diffusivity abnormalities in Leber's hereditary optic neuropathy: A tract-based spatial statistics study. J. Neurol. 2012, 259, 1801-1807. [CrossRef]

17. Takemura, H.; Ogawa, S.; Mezer, A.A.; Horiguchi, H.; Miyazaki, A.; Matsumoto, K.; Shikishima, K.; Nakano, T.; Masuda, Y. Diffusivity and quantitative T1 profile of human visual white matter tracts after retinal ganglion cell damage. NeuroImage Clin. 2019, 23, 101826. [CrossRef]

18. Long, M.; Wang, L.; Tian, Q.; Ding, H.; Qin, W.; Shi, D.; Yu, C. Brain white matter changes in asymptomatic carriers of Leber's hereditary optic neuropathy. J. Neurol. 2019, 266, 1474-1480. [CrossRef]

19. Frisoni, G.B.; Fox, N.C.; Jack, C.R.; Scheltens, P.; Thompson, P.M. The clinical use of structural MRI in Alzheimer disease. Nat. Rev. Neurol. 2010, 6, 67-77. [CrossRef]

20. Ashburner, J.; Friston, K.J. Why Voxel-based morphometry should be used. Neuroimage 2001, 14, 1238-1243. [CrossRef]

21. Riccelli, R.; Toschi, N.; Nigro, S.; Terracciano, A.; Passamonti, L. Surface-based morphometry reveals the neuroanatomical basis of the five-factor model of personality. Soc. Cogn. Affect. Neurosci. 2017, 12, 671-684. [CrossRef]

22. Busatto, G.F.; Diniz, B.S.; Zanetti, M.V. Voxel-based morphometry in Alzheimer's disease. Expert Rev. Neurother. 2008, 8, 1691-1702. [CrossRef]

23. Yasuda, C.L.; Betting, L.E.; Cendes, F. Voxel-based morphometry and epilepsy. Expert Rev. Neurother. 2010, 10, 975-984. [CrossRef]

24. Jiang, J.; Zhu, W.; Shi, F.; Liu, Y.; Li, J.; Qin, W.; Li, K.; Yu, C.; Jiang, T. Thick visual cortex in the early blind. J. Neurosci. 2009, 29, 2205-2211. [CrossRef]

25. Voss, P.; Pike, B.G.; Zatorre, R.J. Evidence for both compensatory plastic and disuse atrophy-related neuroanatomical changes in the blind. Brain 2014, 137, 1224-1240. [CrossRef]

26. Hernowo, A.T.; Prins, D.; Baseler, H.A.; Plank, T.; Gouws, A.D.; Hooymans, J.M.M.; Morland, A.B.; Greenlee, M.W.; Cornelissen, F.W. Morphometric analyses of the visual pathways inmacular degeneration. Cortex 2014, 56, 99-110. [CrossRef]

27. Zhang, Y.; Huang, H.; Wei, S.; Qiu, H.; Gong, Y.; Li, H.; Dai, Y.; Jiang, Z.; Liu, Z. Characterization of retinal nerve fiber layer thickness changes associated with leber's hereditary optic neuropathy by optical coherence tomography. Exp. Ther. Med. 2014, 7, 483-487. [CrossRef]

28. Rocca, M.A.; Valsasina, P.; Pagani, E.; Bianchi-Marzoli, S.; Milesi, J.; Falini, A.; Comi, G.; Filippi, M. Extra-visual functional and structural connection abnormalities in Leber's hereditary optic neuropathy. PLoS ONE 2011, 6, e17081. [CrossRef]

29. Chen, Z.; Liu, M.; Ma, L. Surface-Based Morphometry of Human Brain: Intra-individual Comparison Between 3T and 7T High Resolution Structural MR Imaging. Chin. Med. Sci. J. 2017, 226-231. [CrossRef]

30. Seiger, R.; Hahn, A.; Hummer, A.; Kranz, G.S.; Ganger, S.; Küblböck, M.; Kraus, C.; Sladky, R.; Kasper, S.; Windischberger, C.; et al. Voxel-based morphometry at ultra-high fields. A comparison of 7T and 3T MRI data. Neuroimage 2015, 113, 207-216. [CrossRef] 
31. Duyn, J.H.; Van Gelderen, P.; Li, T.Q.; De Zwart, J.A.; Koretsky, A.P.; Fukunaga, M. High-field MRI of brain cortical substructure based on signal phase. Proc. Natl. Acad. Sci. USA 2007, 104, 11796-11801. [CrossRef]

32. Van Der Kolk, A.G.; Hendrikse, J.; Zwanenburg, J.J.M.; Visser, F.; Luijten, P.R. Clinical applications of $7 \mathrm{~T}$ MRI in the brain. Eur. J. Radiol. 2013, 82, 708-718. [CrossRef]

33. Zaretskaya, N.; Fischl, B.; Reuter, M.; Renvall, V.; Polimeni, J.R. Advantages of cortical surface reconstruction using submillimeter 7 T MEMPRAGE. Neuroimage 2018, 165, 11-26. [CrossRef]

34. Kollia, K.; Maderwald, S.; Putzki, N.; Schlamann, M.; Theysohn, J.M.; Kraff, O.; Ladd, M.E.; Forsting, M.; Wanke, I. First clinical study on ultra-high-field MR imaging in patients with multiple sclerosis: Comparison of 1.5T and 7T. Am. J. Neuroradiol. 2009, 30, 699-702. [CrossRef]

35. Nakada, T.; Matsuzawa, H.; Igarashi, H.; Fujii, Y.; Kwee, I.L. In vivo visualization of senile-plaque-like pathology in Alzheimer's disease patients by mr microscopy on a 7T system. J. Neuroimaging 2008, 18, 125-129. [CrossRef]

36. Stüber, C.; Morawski, M.; Schäfer, A.; Labadie, C.; Wähnert, M.; Leuze, C.; Streicher, M.; Barapatre, N.; Reimann, K.; Geyer, S.; et al. Myelin and iron concentration in the human brain: A quantitative study of MRI contrast. Neuroimage 2014, 93, 95-106. [CrossRef]

37. Keuken, M.C.; Bazin, P.L.; Backhouse, K.; Beekhuizen, S.; Himmer, L.; Kandola, A.; Lafeber, J.J.; Prochazkova, L.; Trutti, A.; Schäfer, A.; et al. Effects of aging on T1, T2*, and QSM MRI values in the subcortex. Brain Struct. Funct. 2017, 222, 2487-2505. [CrossRef]

38. Uludağ, K.; Blinder, P. Linking brain vascular physiology to hemodynamic response in ultra-high field MRI. Neuroimage 2018, 168, 279-295. [CrossRef]

39. Vergani, L.; Martinuzzi, A.; Carelli, V.; Cortelli, P.; Montagna, P.; Schievano, G.; Carrozzo, R.; Angelini, C.; Lugaresi, E. MtDNA mutations associated with leber's hereditary optic neuropathy: Studies on cytoplasmic hybrid (cybrid) cells. Biochem. Biophys. Res. Commun. 1995, 210, 880-888. [CrossRef]

40. Klivenyi, P.; Karg, E.; Rozsa, C.; Horvath, R.; Komoly, S.; Nemeth, I.; Turi, S.; Vecsei, L. $\alpha$-tocopherol/lipid ratio in blood is decreased in patients with Leber's hereditary optic neuropathy and asymptomatic carriers of the 11778 mtDNA mutation. J. Neurol. Neurosurg. Psychiatry 2001, 70, 359-362. [CrossRef]

41. Lodi, R. 'Secondary' 4216/ND1 and 13708/ND5 Leber's hereditary optic neuropathy mitochondrial DNA mutations do not further impair in vivo mitochondrial oxidative metabolism when associated with the 11778/ND4 mitochondrial DNA mutation. Brain 2000, 123, 1896-1902. [CrossRef]

42. Ogawa, S.; Takemura, H.; Horiguchi, H.; Terao, M.; Haji, T.; Pestilli, F.; Yeatman, J.D.; Tsuneoka, H.; Wandell, B.A.; Masuda, Y. White matter consequences of retinal receptor and ganglion cell damage. Investig. Ophthalmol. Vis. Sci. 2014, 55, 6976-6986. [CrossRef]

43. Manners, D.N.; Rizzo, G.; Morgia, C.L.; Tonon, C.; Testa, C.; Barboni, P.; Malucelli, E.; Valentino, M.L.; Caporali, L.; Strobbe, D.; et al. Diffusion tensor imaging mapping of brain white matter pathology in mitochondrial optic neuropathies. Am. J. Neuroradiol. 2015, 36, 1259-1265. [CrossRef]

44. Cui, S.; Yang, L.; Jiang, H.; Peng, J.; Shang, J.; Wang, J.; Zhang, X. Clinical Features of Chinese Sporadic Leber Hereditary Optic Neuropathy Caused by Rare Primary mtDNA Mutations. J. Neuroophthalmol. 2020, 40, 30-36. [CrossRef]

45. Borrelli, E.; Triolo, G.; Cascavilla, M.L.; Morgia, C.L.; Rizzo, G.; Savini, G.; Balducci, N.; Nucci, P.; Giglio, R.; Darvizeh, F.; et al. Changes in Choroidal Thickness follow the RNFL Changes in Leber's Hereditary Optic Neuropathy. Sci. Rep. 2016, 6, 37332. [CrossRef]

46. Wang, L.; Fan, K.; Zhang, Y.; Chen, Y.; Tian, Q.; Shi, D. Quantitative assessment of optic nerve in patients with Leber's hereditary optic neuropathy using reduced field-of-view diffusion tensor imaging. Eur. J. Radiol. 2017, 93, 24-29. [CrossRef]

47. Wang, M.; Guo, H.; Li, S.; Wang, G.; Long, Y.; Meng, X.; Liu, B.; Liu, Y.; Robson, A.G.; Yin, Z.Q. Electrophysiological and Structural Changes in Chinese Patients with LHON. J. Ophthalmol. 2020, 2020, 4734276-4734279. [CrossRef]

48. Ott, B.R.; Cohen, R.A.; Gongvatana, A.; Okonkwo, O.C.; Johanson, C.E.; Stopa, E.G.; Donahue, J.E.; Silverberg, G.D. Brain ventricular volume and cerebrospinal fluid biomarkers of alzheimer's disease. J. Alzheimer's Dis. 2010, 20, 647-657. [CrossRef]

49. Camicioli, R.; Sabino, J.; Gee, M.; Bouchard, T.; Fisher, N.; Hanstock, C.; Emery, D.; Martin, W.R.W. Ventricular dilatation and brain atrophy in patients with Parkinson's disease with incipient dementia. Mov. Disord. 2011, 26, 1443-1450. [CrossRef] 
50. Tabrizi, S.J.; Reilmann, R.; Roos, R.A.C.; Durr, A.; Leavitt, B.; Owen, G.; Jones, R.; Johnson, H.; Craufurd, D.; Hicks, S.L.; et al. Potential endpoints for clinical trials in premanifest and early Huntington's disease in the TRACK-HD study: Analysis of 24 month observational data. Lancet Neurol. 2012, 11, 42-53. [CrossRef]

51. Blatter, D.D.; Bigler, E.D.; Gale, S.D.; Johnson, S.C.; Anderson, C.V.; Burnett, B.M.; Ryser, D.; Macnamara, S.E.; Bailey, B.J. MR-based brain and cerebrospinal fluid measurement after traumatic brain injury: Correlation with neuropsychologicai outcome. Am. J. Neuroradiol. 1997, 18, 1-10. [PubMed]

(C) 2020 by the authors. Licensee MDPI, Basel, Switzerland. This article is an open access article distributed under the terms and conditions of the Creative Commons Attribution (CC BY) license (http://creativecommons.org/licenses/by/4.0/). 